\title{
HOUR BY HOUR OPERATION OF FEXED AND SWITCHED CAPACITOR BANK CONNECTED TO A RADIAL DISTRIBUTION FEEDER
}

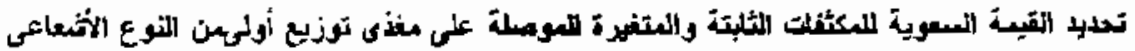

\section{S. S. Eskander}

A. M. M Aly

Flectrical Power and Machines Department, Faculty of Engineering, EL,-Mansourn University, EL-Mansoura, Egypt

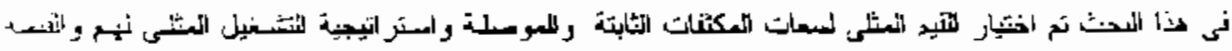

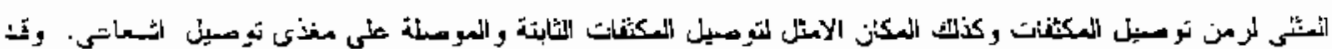

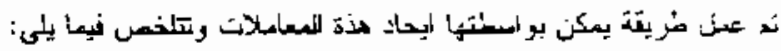

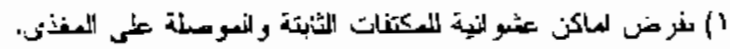

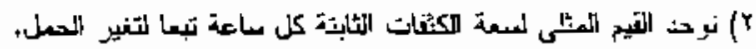

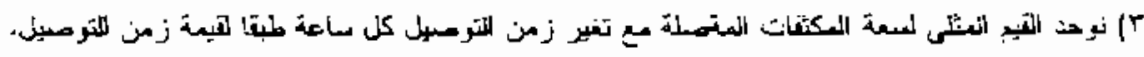

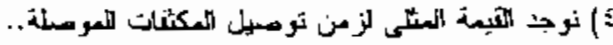

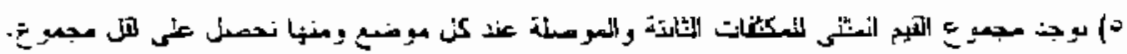

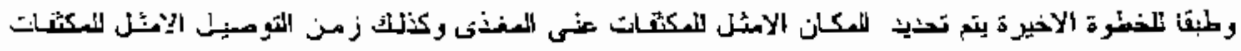

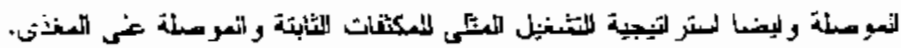

\section{ARSTRACT}

This paper gives snethod for seiecting optimurn position for fixed and switched capacilors on a radial feeder. The optinum position of capacitors ( fixed and switched ) are selected based on random proposal for their places on the feeder. The method also includes a selection of optimum switching time of switched capacitor which will be located at the optimurn position. As the optimum location is defnite, the hourly optimum operating strategy for bxed and switched vapacitors located at the optimum positions is obtained.

\section{INTRODUCTION}

Pawer capacitors have been irrproved tremendously over the last 30 years or so. party due to improvements in the dielectric materials and their more efficient urilization and party duc to inprovements in the processing techniques iuvolved. Capacitor sizes have increased from the 15 - 25 KVAR range to the 200 - 300 KVAR range (eapacitor banks are usually supplied in sizes ranging from 300 - 1800 KVAR ). Now days, power capacitors are much more efficient than those of 30 years ago and are available to the electric utilities at a much lower cost per kilovar 
In general, capacitors are getting more attention today than before, partly due to a new dimension added in the analysis : change out economics [1].

Kilovars, as well as kilowatts, must be provided to the customer as part of a utility's electricity service, and the analysis of the technically most desirable and economically most attractive way to supply this reactive power requirement is one of the system planner's objectives. Where as the kilowarts can be supplied only from an energy source or power plant. kilovars are automatically produced as well as consumed by the electric network itself. This. of course. results from the inherent sbunt - capacitive and series - inductive characteristics of the transmission lines. For this reasons planning of the reactive power supply is subjected to a greater range of system variables [2].

A technique is developed for solving the voltampere reactive (VAR) compensation prohlers under uncertain operating conditions. The techuique employs chance - constritined programming (CCP), and transforms the probjcm into a standard livear programming problenı. ‘ providing optimal allocation of VAR supports, busbars with unacceptably which probabiiur: of violating voltage limits are identified and assigned appronniate thance - constrainss. ' w+ cilses are considered using the new technique. In the lirst cir: for peax load conditious. Inductive compensation is consuci:ured nt the secol i case. il ing light load couditions [3].

A methodology for finding the degrees of series sapacitor and shuut - reactor compensation is used to increase the power transfer capability of the over - head power transmission existing rights of way and to get adequate control of steady state voltage and reactive power requirenents. Tus methodology is based on assumed system design criteria and takes into consideration several schemes of compensation [4].

A transposition study carried out on the $654 \mathrm{Km} \mathrm{Muja} \mathrm{-} \mathrm{Kalgoorlie} 220 \mathrm{Kv}$ radial transmission systcin are presented. Voltage control and stabilization of his nerwork is achieved with the installation of three saturated reactor type static VAR compensalors. By suitable line transposition. it is shown how voltage imbalances at the stalic voltage capacitors locations can be reduced to ensure minimal negative phase sequence current loading on the saturated - reactors [5].

The paper presents a method for obtaining optimum positions, optimum capaciror hank sizes ( fixed and swiched ), optimum switching time and optimun operating strategy for fixed and switched capacitor is obtained. The method is based upon Grainger and Lee equarions[6, 7].

\section{PROBLEM FORMTLATION}

The problem here is the determination of optimum positions. oprimum capacitor sizes, optimum switcbing time and optimum operating strategy for fixed and swirched capacitors connected with radial feeder. The methol for obtaining the above mentioned parameters are obtaiued hy the following steps:

In the firs. a selection of random positions for fixed and switched capacitors is carried out. Then. a seleccion of the optimum places, optimum capacitor sizes (liwed alld switched ), optimum switching time and optimum operating strategy are obtained. The : ruvious parameters are deternimed as follows: 


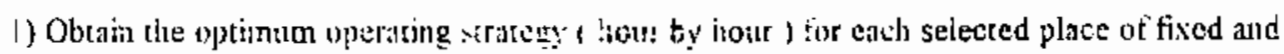
switched cnpacitors.

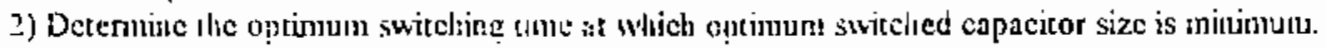

3) Obtain the suu of optimm tixeu anci switched capacitor sizes at each selected places ant sclect the iminimum sumumatton.

4) Rȩ̣reseit section mubers at whicit manimum sughnatiou are onrained.

The feetier under investigation insiss of 9 sections and is supplied from a substation. Fle ficeder is loaded with time - varyme loalls cowecred with it through ir's letgch at each node.

Suppose there are $K$ scctions in the physical teeder shown in fig.(1). Cloose $r_{j}$, the resistance in olwas per auic length of the ith secron. as the resisiance in obms per unit lenglu of Ihe equivalent uniromi leeder. Modify tue physical lesguth $L_{i}$ of the ith as follows [6. 7].

$$
\mathrm{L}_{\mathrm{ui}}=\frac{\mathrm{L}_{\mathrm{i}} \mathrm{\Gamma}_{\mathrm{i}}}{\mathrm{r}_{\mathrm{j}}} \quad \mathrm{i}=\mathrm{i}, 2,3, \quad \mathrm{k}
$$

Whace $L_{u i}$ is the length of the jeh secrion of the equivalitut unifonn reeder.

$L_{u}$. thc total lengrts of the equivaieut uniform fèder is iletiled by:

$$
\mathrm{L}_{\mathbf{u}}=\sum_{\mathrm{i}=1}^{k} \frac{\mathrm{L}_{\mathrm{j}} \cdot \mathrm{r}_{\mathrm{i}}}{\mathrm{r}_{\mathrm{j}}}
$$

Divide ack sectiou leagrl $L_{\text {vi }}$ of the equivalcut feeuer by $L_{u}$ io vield a normaiized equivalcn uniforn feeder of uuity length and uxiform rcsistance

$$
r=\sum_{i=1}^{k} L_{i} r_{i}
$$

ohtns per nomalized unit length

We now jefine a nonaaiized resctive current density fuuction. $f(x)$, and a nommalized feeder reacrive current function. $\Gamma(x)$, as follows $[6,7]$ :

$$
\begin{aligned}
& f(x)=\frac{l(x)}{l_{s}} \\
& F(x)=\sum f(\tau) \quad x \leq \tau \leq 1
\end{aligned}
$$

Wherc $\mathrm{I}_{\mathrm{S}}$ is the reactive urrent injected into lue feeder at the substation. $x$ is the distance measured along the uormalized equivalent tiniform ferder from the same end aud $I(x)$ is the lesctive cimreut density al $x$.

fo provide the most genteril soltinon procedures so that distribution engincers can apply the solution tccluniques to design problens of diflerent nature, the followiug nocation is used tliroughout tie scudy. As shown mig. (1) I lixed and .' or switched loanks are consecutively numbered from the end of the feetior tow arit the substarion.

The locarions are incasured fron ids wabstution and are represented by $h_{i}, j=l$, 2.........., n. The per unit bank sizcs ( at nor:nat prinar. volage ) are denored by $I_{\mathrm{ci}}, j=1$.

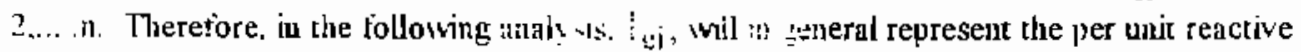

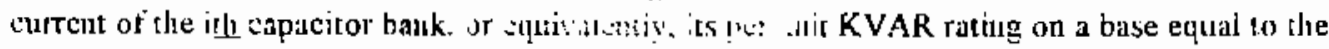


maximum value af the reactive load in the feeder. The type of cach capacitor, :xtich is not specified in fig.( 1 ) be represented by using the following sct notation.

Let $M$ and $N$ be the sets of idices of fixed and switched eapacitor banks, respectively. For example, if the ith bank is a switclied one, it will be represented as $I \in N$. Let LP denote the peak power aud energy loss reduccions whicb resuit from tbe capacitor's placement. Then LP is given by [6.7]:

$$
\begin{aligned}
& L P=3\left[\int _ { 0 } ^ { 1 } \left(I_{s} F(x)^{2} r d x-\underset{0}{\left(h_{n}^{n}\right.}\left(I_{s} F(x)-\sum_{j=l}^{N} I_{c j}\right)^{2} r d x+\right.\right. \\
& \left.\left.\sum_{i=1}^{n-1} \int_{i_{i=1}}^{i_{i}}\left(1_{s} F(x)-\sum_{j=1}^{i} I_{c j}\right)^{2} r d x+\int_{i_{1}}^{1}\left(I_{s} F(x)\right)^{2} r d x\right)\right]
\end{aligned}
$$

The energy loss reduction can be written in the form of

$$
\begin{gathered}
L E=3 \int_{0}^{T_{s}}\left(I_{s}(t) F(x)\right)^{2} r d x-\left(\int_{0}^{h_{n}}\left(I_{s}(t) F(x)-\sum_{j=1}^{n} I_{c j}\right)^{2} r d x+\right. \\
\left.\left.\left.\sum_{i=1 h_{i-1}}^{n-i} \int_{h_{j}}^{h_{j}}\left(J_{s}(t) F(x)-\sum_{j=1}^{i} I_{c j}\right)^{2} r d x+\int_{b_{i}}^{l} l_{s}(t) F(x)\right)^{2} r d x\right)\right) d t
\end{gathered}
$$

Where $I_{S}(t)$ is the time-varying reaccive load curent over a load cyede of duration $T$ at the subsation end of the noruatized equivalent uniform reeder of resisance $r$ olms per unit length. and its variacion siown in able $(t)$. The net savings function to be maximized is then given by:

$$
S=K_{p} L P+K_{e} L E-K_{c f} \sum_{\substack{i=1 \\ i \in M}}^{n} I_{c i}-K_{c s} \sum_{\substack{i=1 \\ i \in N}}^{n} I_{c i}
$$

\section{OFTLMUM BANK SIZES}

If the loeations of the fixed and switched banks are known, aud if the swirching time of the switclied banks is predeternined the bank sizes can be determuned by solving the following sec of jinear equations for $I_{c}$ :

$[\mathrm{H}]\left[\mathrm{I}_{\mathrm{C}}\right]=[\mathrm{D}]$

Wherc $\left.I_{c}=\left[I_{c l},\right]_{c 2}, \ldots . I_{c n}\right]^{\mathbf{l}}$ is the $n$ dimensional colume vector to be determined.

and the $n$ * $\mathrm{n}$ Inatrix $\mathrm{H}$ and the $\mathrm{n}$ dimensional column vector $\mathrm{D}$ : $\mathrm{re}$ nven as follows:

For $\mathrm{i} \geq \mathrm{j}$, 
$H_{i j}=\left\{\begin{array}{ll}h_{i}\left(K_{p}+K_{e} T\right) & \text { if both } i \text {, and } j \in M \\ h_{i}\left(K_{p}+K_{e} T_{s}\right) & \text { othernise }\end{array}\right\}$

and for $\mathrm{i}<\mathrm{j}$

$H_{i j}=\left\{\begin{array}{ll}h j\left(K_{p}+K_{e} T\right) & \text { if both } i \text { and } j \in M \\ h j\left(K_{p}+K_{e} T_{s}\right) & \text { otherwise }\end{array}\right\}$

$D_{k}=\left\{\begin{array}{c}-\left(K_{p}+K_{e} T \cdot L_{f}\right) \int_{0}^{h_{k}} I_{s} F(x) d x-\frac{K_{c f}}{2 r} \ldots . . i f . k \in M \\ L\left(K_{p}+K_{e} T_{s} L_{f s}\right) \int_{0}^{h_{k}} I_{s} F(x) d x-\frac{K_{c f}}{2 r} \ldots i f \cdot k \in M\end{array}\right.$

The canstants $\mathrm{K}_{\mathrm{p}}, \mathrm{K}_{\mathrm{e}}, \mathrm{K}_{\mathrm{cf}}, \mathrm{K}_{\mathrm{cs}}$ and $\mathrm{t}$ are chosen as follows:

$\mathrm{K}_{\mathrm{p}}=0.329 / \mathrm{kw} / \mathrm{day} . \mathrm{K}_{\mathrm{e}}=1.5 \mathrm{pr} / \mathrm{kwh}, \mathrm{K}_{\text {of }}=\$ 3.5 /$ three - phase KVAR

$\mathrm{K}_{\mathrm{cs}}=\$ 0 /$ three - phase $\mathrm{KVAR}, T=24$. hours

$\mathrm{L}_{\mathrm{f}}$ : is the daily load factor

$\mathrm{L}_{\mathrm{fs}}$ : is switched loakl factor

The feeder under study is represented in tig.(1). It consists of nine sections with differcnt areas and lengils. The clata for each section is demonstrared in the same figure.

\section{GIVEN DATA}

The given data are as follows:

1) Daily load curves at each node of the feeder are illustrated in table(1).

2) Fixed capacitor cost per three phase $K V A R, K_{c f}$.

3) Suvitched cnpacitor cost per three phase KVAR, $K_{c s}$.

4) Cost of KW per day, $K_{p}$.

5) Cost of energy / day, $K_{e}$.

6) Locations of fixed and switched capacitor barks. $h_{i}$.

7) Duration of switched capacitor bauks, $T_{\mathbf{s}}$. 


\section{FLOW CHART}

The hour by hour fixed and switched capacitor sizes are detemined by using the following steps:

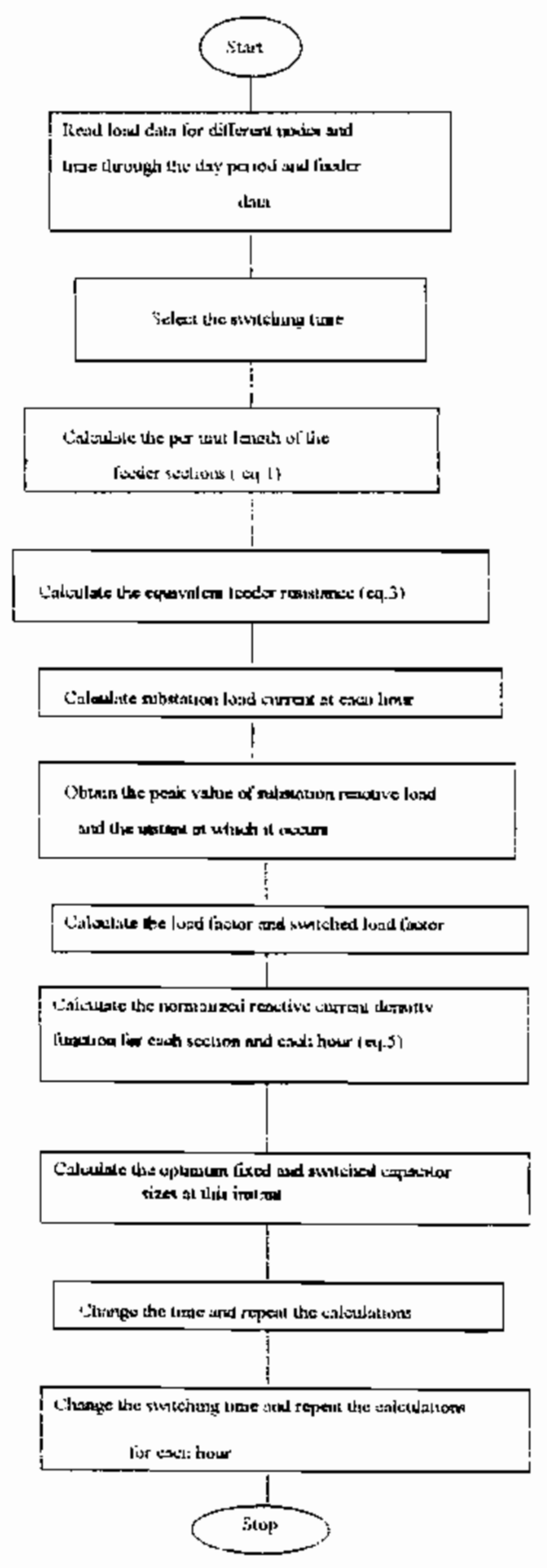

Computer jrogane stejs 


\section{RESULTS}

The problem is programmed for different values of a switching tme. $T_{5}$, and differcut locations of a fived and switched capacitors on the feeder. Results of calculations are represented in the family of curves. These curves iifistr to the optimum fixed and switched capacitor sizes.

Fig. 2 illustrates optinnun size of ixed and switched capacitor against time. The fixed capacitor is located at section 2 where swil hed coptcitor locates at section 5 on the feeder. The switching time for switched capacitor is being 4 bours. From the figure. the maximum size of fixed capacitor bauk ( operates all time) and switched capacitor ( operates only switching time which is equal 4 houres in this case) are obuived and represent in table (3). Figures 3 to 9 give also the relationshipes between fixed capacitor size and time as well as swiched capacitor size and switching time. The positions of capacitors ( fixed and swirched ) on the feeder as well as switching time are changed Figures 2 to 9 illuarate also the values of fixed and switched sapacitors ds well as the instauts at which they happned. The figures represent the optimum uperating strategy for fixed and switchcd capacitors located at the definite nodes for each houres.

Fig. 10 represents the swirched capacitor size, located at section 4, against switching time. The switching time has values $3,6,9,12$ and 15 houres The instants at which switched capacitor has : I Inaximum value is 23 . At this instant the load takes approximately its maximum value. Fig. Il gives the relationshipe between switched capacitor size and the switched time. The relation is approximately linearely decreased from $T_{s}=3$ to $T_{t}=11$ houres from $T_{s}=11$ to 12 houres ic is linear and rapidaly increased. Then. the switched capacitor size is slowly decrcased when $T_{s}=12$ to 17 houres. The beltaviours of switching capacitor size against swiching tim at instants 23 and 24 are similiar. The recomindation obtained from this figure is that the best selection of switching time is in the range from 3 to 11 houres. In this range. the switcling alpacitor size takes a small values and it has a lower value at $T_{s}=11$ houre.

Tahle 3 represents that for all instants from 8 to $24 \mathrm{hr}$ the mimimum size of switching capacitor obtained with swirching time 11 houres. The table gives also the positions of fixed and switched capacitors $N_{F}$ and $N_{2}$ on the feeder, switching time, maximum size of fixed and swilched capacitors. The table illustrates also the summation of maximum values of fixed aud switched capacitors. The selection of the bes position of fixed and switched capacitors on the feeder is the one at which the previous summation has minimum value. The table stows that the location of fixed capacilor is at section + where the position of switched capacitor is at section 8. The operating time of switcred capaciror posioned at section $\mathbf{8}$ on the feeder is II houres as noticed from tig. 11 .

Now the optimum operating strategy of fixed and swilched capacitor banks is detennined. Fig. 7 represents this strategy and gives the hour by bour tixed and switched cupacitor banks size connected to the feeded under reasarch. This figure gives the optimum operating strategy for tixed and switched capacitors located at sectious 4 and 8 respectivity. Sections 4 and 8 represem the optimum places at which fixed and switched capacitors are connected.

\section{CONCLUSIONS}

This paper gives the method for obtaing optinum locations, oprimum capacitor sizes and the optimum operating stralegy for fixed and switched capacitor hanks connected with radial feeder. The method is based upon Graiuer aud Lee equations. In the first. a selection of randoum positions for fixed and swiched capacitor is carried out. Then. a selection of the optimum places. opcimum capacitor sizes ( fixed and switched), optimum switching time and optimum operating strategy are obtained. The previous paramerers are determined as follows: 
1) Obtain the optimum operaing strategy (hour by bour) for each seleeted place of fixed and switclied capacitors.

2) Determine the optimum switching time at wlich optirmum switched capacitor size is minimum.

3) Obtain the sum of optimum fixed and swicchcd capacitor sizes at each selected places and select the miainum summation.

4) Represent section Iumbers at which minimuln sunnmation are obtained.

By using the above inentioned method on the radial feeder under invistigation. tbe optunum optimum values of previous parameters which are: optimumn locations of fixed and switched capacitors are being at sections 4 and 8 , optimum switcling time is 11 houres and the optirnum operating strategy for fixed and swiccbed capacitors is obtained.

\section{REFERENCES}

1. T. Longland, T. W. Hant, A. Brecknell " Power capacitor handbook ", Book. 1985.

2. Nagel, T. j., and Vassell. G. S. : "Basic principies of planwing VAR coutrol on the annent.." electric power syrem "IEEE trans. 1968. PAS-87. pp. $488-495$.

3. T. A. M. Sharaf and G. J. Berg "Voltannere renctive counpestsation utíng chance-constrained propramming "IEE PROC., vol. 129. pt.c. No. ! binuary :982

4. M. EL-Marsafawy " Application of seties-capacitor und unt-reacior comps " ation 10 an existiug practical AC transmission ime "IEE PROCEEDINGS, vol. 138. No. 4, July 1צ४ו

5. S. S. Choi "Transposition study and ficld measurements of long radial-reactrve power sompensated transınission system "IEE PROCEEDINGS. vol. 138. No. 4. July 1991.

6. S. H. Lee and J. J. Grainger "Optimum placement of fixed anci suitched capacitors on primary distribution feeders" IEEE transaction on power apparatus and stustems, vol. PAS 100, No. 1. Jauuary, 1981 .

7. J. J. Grainger and S. H. Lce "Optimnm size and location of shumt capacitors for reduction of losses on distribution feeders "IEEE transaction on power apparatus and systems, vol. PAS-100. No. J. March. 1981.

\begin{tabular}{|l|l|l|l|l|l|l|l|l|l|}
\hline 1 & 1 & 2 & 3 & 4 & 5 & 6 & 7 & 8 & 9 \\
\hline 2 & $\mathrm{Cu}$ & $\mathrm{Au}$ & $\mathrm{Cu}$ & $\mathrm{Cu}$ & $\mathrm{Cu}$ & $\mathrm{Cu}$ & $\mathrm{Cu}$ & $\mathrm{Cu}$ & $\mathrm{Cu}$ \\
\hline 3 & 300 & 336 & $2 / 0$ & 2 & 2 & 2 & 4 & 4 & 4 \\
\hline 4 & .63 & .88 & 1.7 & .81 & 2.3 & 1.05 & 1.5 & 3.5 & 3.9 \\
\hline 5 & .2 & .28 & .44 & .86 & .86 & .86 & 1.37 & 1.37 & 1.37 \\
\hline 6 & .14 & .29 & .866 & .81 & 2.3 & 1.05 & 2.38 & 5.56 & 6.15 \\
\hline 7 & 1.01 & 015 & .044 & .041 & .117 & .054 & .122 & .284 & .316 \\
\hline
\end{tabular}

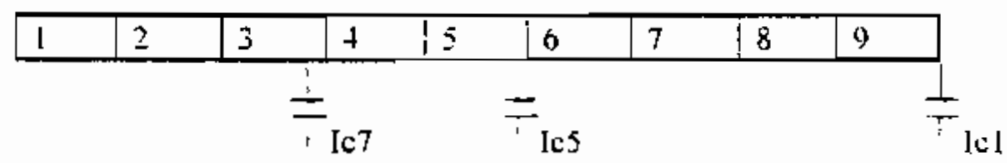

Fig.( I) Representation of teeder sections and its data

1- Section number

j- Cross Sectional areas inn 2

5- Sections resistance ohm/inde
2- Cable muaterials

4- Section length in mile

6- Section length of equivalent mitrom teeder in mile

7- Normalized section length for equivalent unifonn feeder. 


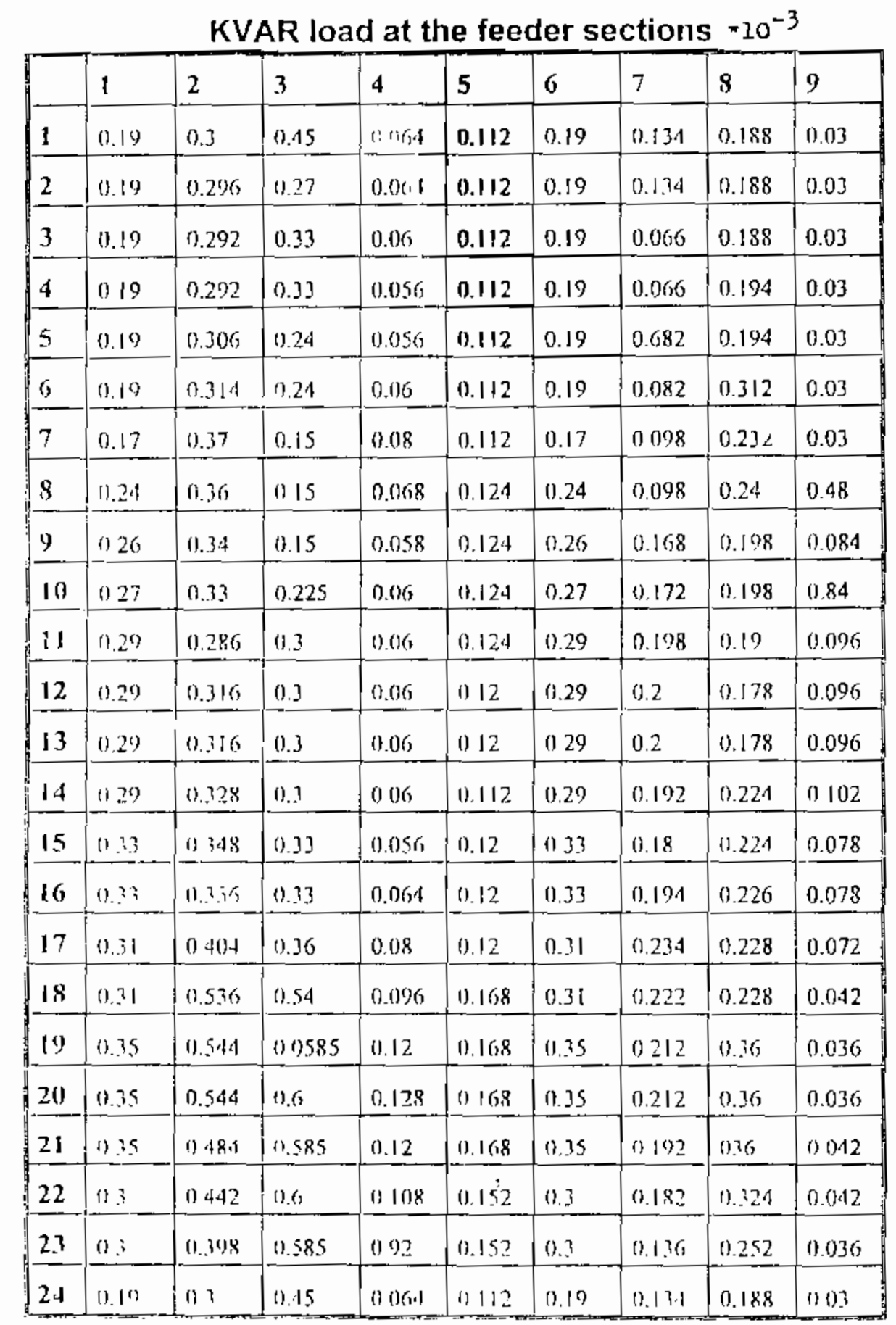

Table(1) Load-Tine characteristics at different nodes 


\begin{tabular}{|c|c|c|c|c|c|c|c|c|c|c|c|c|c|c|c|c|c|}
\hline B & $\Rightarrow$ & 10 & 11 & 12 & 13 & 14 & 15 & 16 & $1 \%$ & $1 \mathrm{H}$ & 19 & 2.0 & 21 & 22 & 23 & $244^{1-}$ & $\mathrm{H} / \mathrm{C}$ \\
\hline - & - & - & - & - & - & - & - & - & - & - & - & - & - & 792 & 1700 & 618 & 3 \\
\hline- & - & - & - & - & - & - & - & - & - & - & -1 & - & 726 & 749 & 1582 & 510 & 4 \\
\hline - & - & - & - & - & - & - & - & - & - & 一 & - & :225 & 6715 & 103 & $4 \% 3 !$ & 544 & 5 \\
\hline- & - & - & - & - & - & $\sim$ & - & - & - & - & 657 & 683 & 637 & 663 & $13 \%$ & 511 & 6 \\
\hline. & - & - & - & - & - & - & - & - & - & 607 & 6200 & 0.3 & 610 & 632 & 1300 & 485 & 7 \\
\hline- & - & -1 & - & - & - & - & - & - & 324 & 590 & 13 & 536 & 95 & 613 & 243 & $4 \%$ & is \\
\hline- & - & .. & - & - & - & - & - & 271 & 328 & 579 & 604 & 626 & 587 & 602 & 139 & 1.50 & 9 \\
\hline - & - & - & - & - & - & - & 276 & $\mid 2 \%$ & $|331|$ & : & ' & 618 & 580 & 1592 & - & +.tai!! & i \\
\hline- & - & - & -1 & - & - & $254:$ & 201 & 28 & | & $\because 61$ & ' & !610 & 574 & $\therefore-4$ & $|124|$ & $|440|$ & i i \\
\hline .- & - & - & $-\quad$ & - & 713 & 748 & 790 & $\{801\}$ & 867 & 1120 & ; 12344 & 125 & $\cdot 121$ & -1 & 1796 & 422, & 12 \\
\hline- & $-\quad$ & - & - & 731 & 210 & $\mid 2407$ & | 780 & 798 & | $862 \mid$ & i ל 11 & i 1220 | & 11242 & 1196 & 1145 & $|1 ; 58|$ & 1309 & I: \\
\hline- & -1 & - & 721 & | & 704 & $743 \mid$ & $782\}$ & 794 & uss & $1090^{\circ}$ & 11204 & | & 101 & 1129 & 1720 & 796 & 1: \\
\hline- & - & 867 & $\gamma_{1}$ & $/ 22$ & 698 & 739 & 770 & $>80$ & 848 & $10 \% 3$ & 1288 & 1208 & 1165 & 11112 & 1684 & 783 & 12 \\
\hline- & goo í & $|x \geqslant 2|$ & 710 & 118 & 697 & 733 & 769 & 781 & 839 & 1057 & $\mid 1171\}$ & 1191 & $11 / 8$ & 1095 & 1650 & $|70|$ & 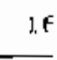 \\
\hline 7 & 804 & $3 / 1$ & ; & 104 & 6044 & 726 & $6 / 1$ & 173 & 830 & $50 \times 1$ & |1143! & 1173 & 1132 & 1070 & 1614 & 757 & 17 \\
\hline
\end{tabular}

Table(2) joitcied capac1ior size, locates at node 4, in TîA agains time vith differenc switcning iine.

\begin{tabular}{|c|l|l|l|l|l|l|l|l|}
\hline Nr & 2. & 4 & 3 & 4 & 2 & 4 & 2 & 3 \\
\hline Ns & 5 & 8 & 7 & 8 & 5 & 8 & 5 & 7 \\
\hline Ts & 4 & 3 & 3 & 11 & 10 & 11 & 7 & 5 \\
\hline Cfmax & 3389 & 3444 & 1900 & 1514 & 3200 & 1582 & 3300 & 2143 \\
\hline$C_{\text {smax }}$ & 1444 & 417 & 1100 & $771 !$ & 375 & 800 & 400 & 893 \\
\hline Cfmax + Csmax & 3833 & 3861 & 3000 & 2285 & 3575 & 2382 & 3700 & 3030 \\
\hline
\end{tabular}

Table 3 Maximun Capacitance of Fixed and Switclsed Capacitor Banks and Their Optimum Locations

Ne. Locition of fixed tapacitor.

$N_{s}$ : Location of switched cipacitor.

Ts. Swilching timee.

Clinax. Csinax : are the maxinum capacitauces of fixed and sunterieci capacitor 
CAPACITOR SIZES KVAA

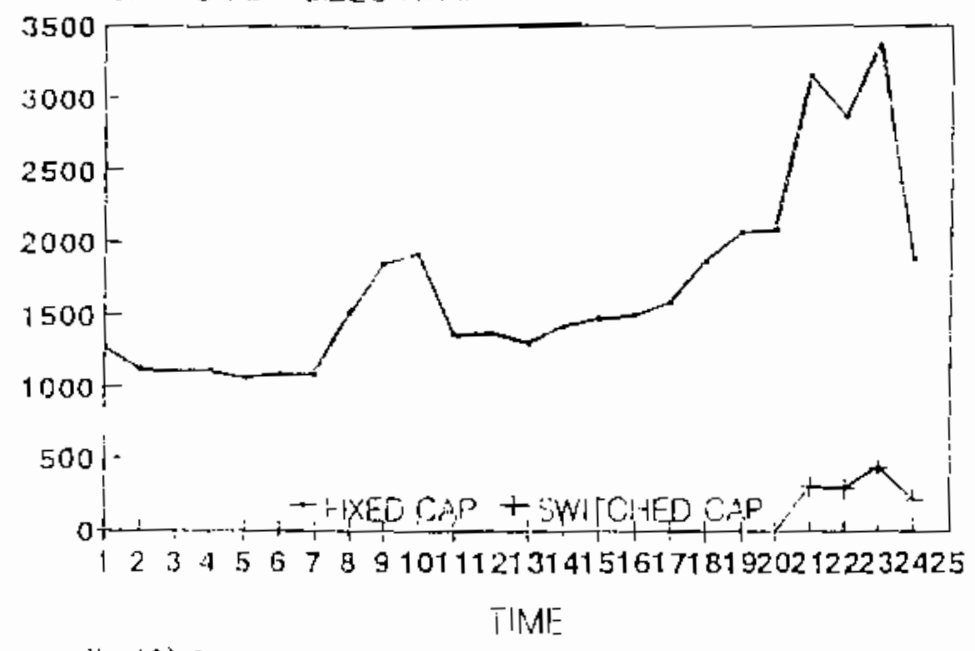

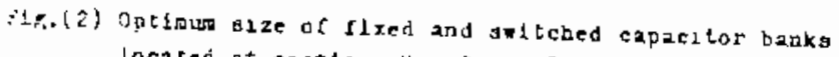
localé at soetlons No. 2 and 5 for swiching rine 3 bours.

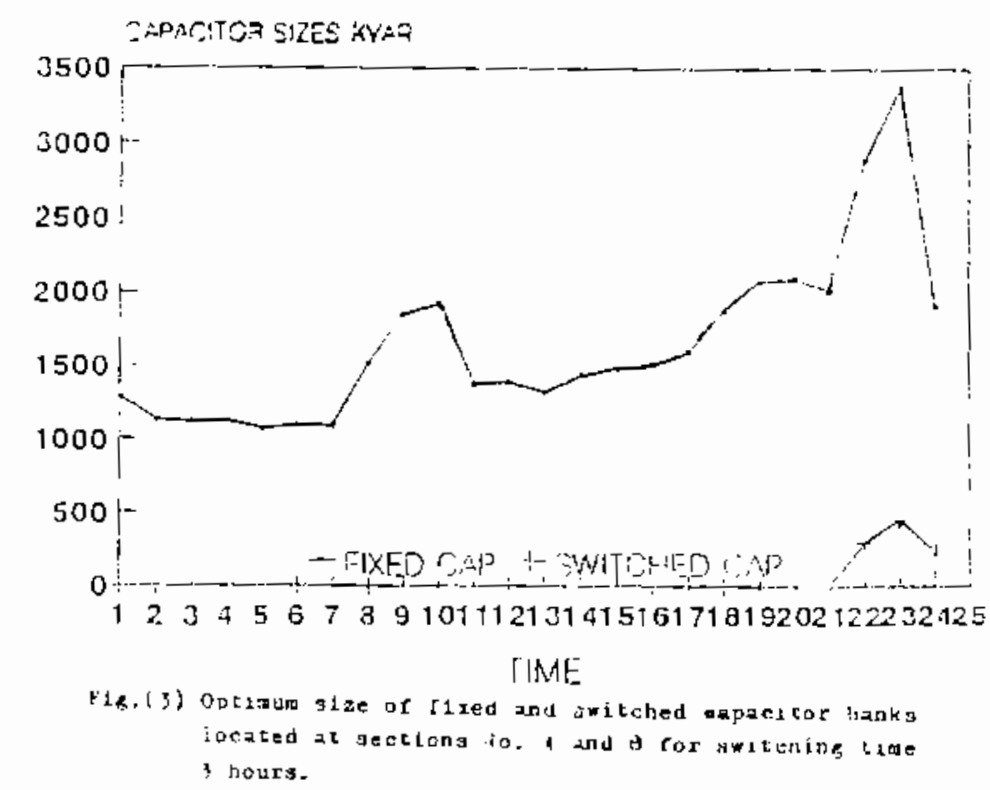



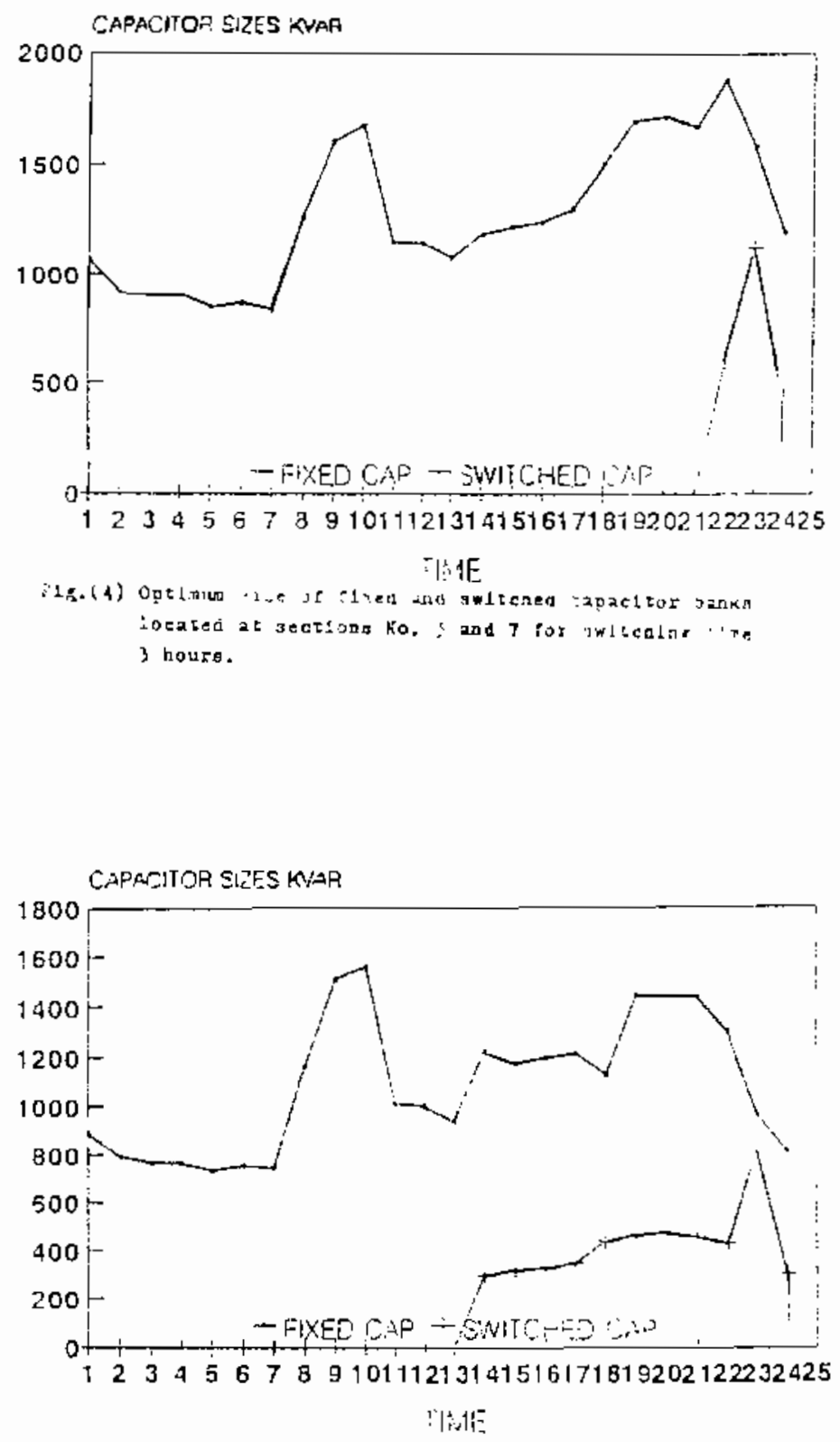

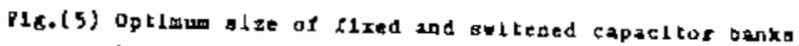

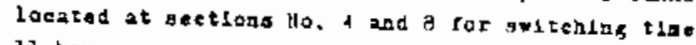
11 houra. 


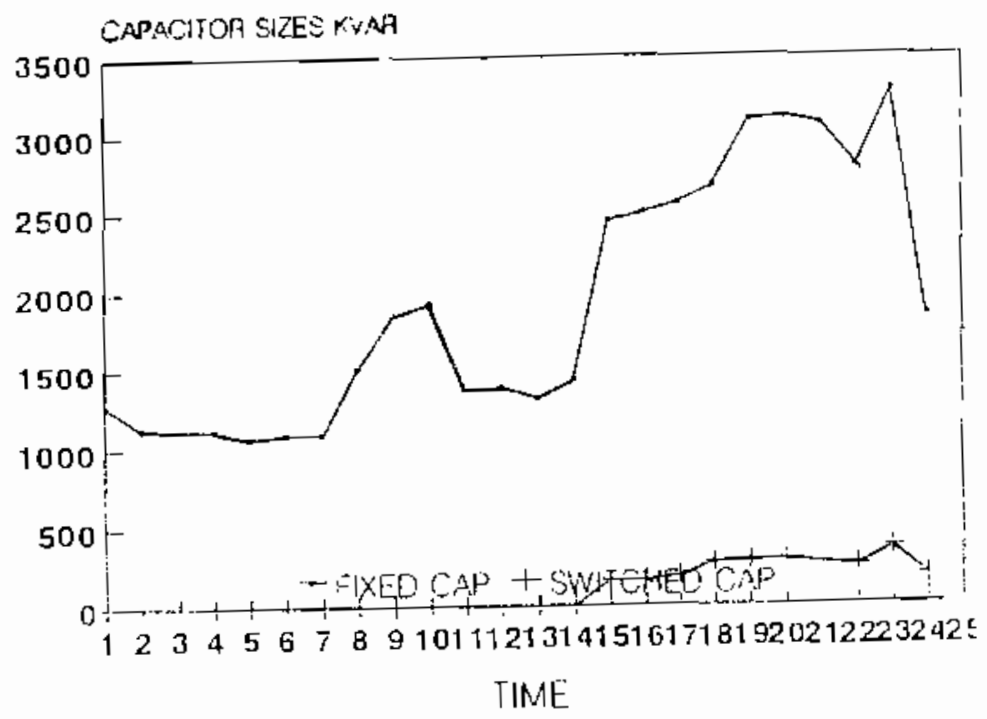

P15. (6) 0ptlan size of rixed and switched capacitor banks loozted at sections Ho. 2 and 5 for sultang lime il nours.

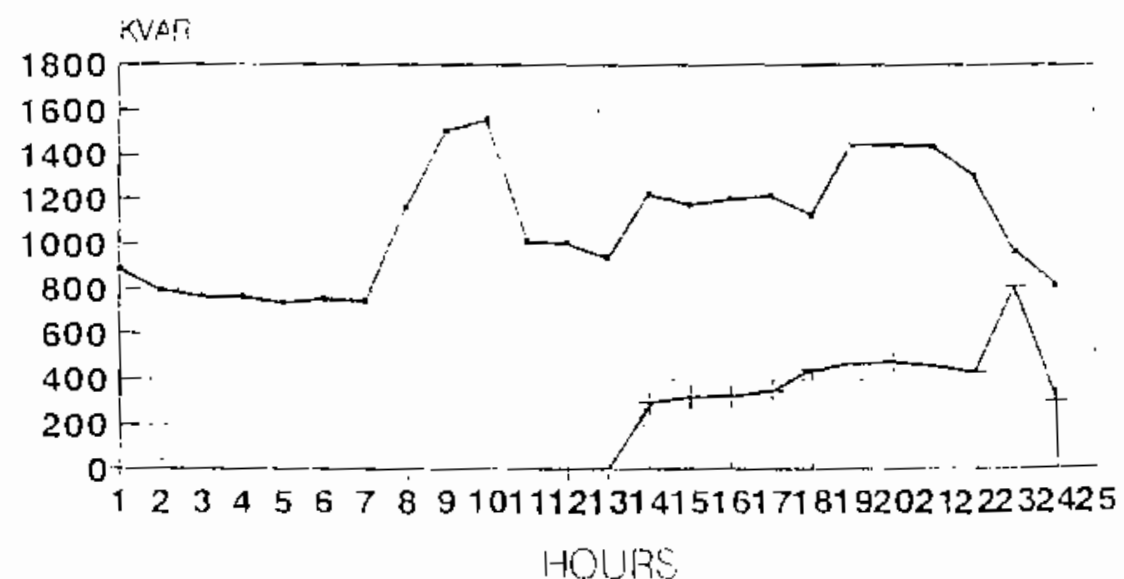

8ig.17) Optimus size of fixed and soltched capacitor banks located ze uections xo. 4 and 8 for jultehing the 11 hours. 

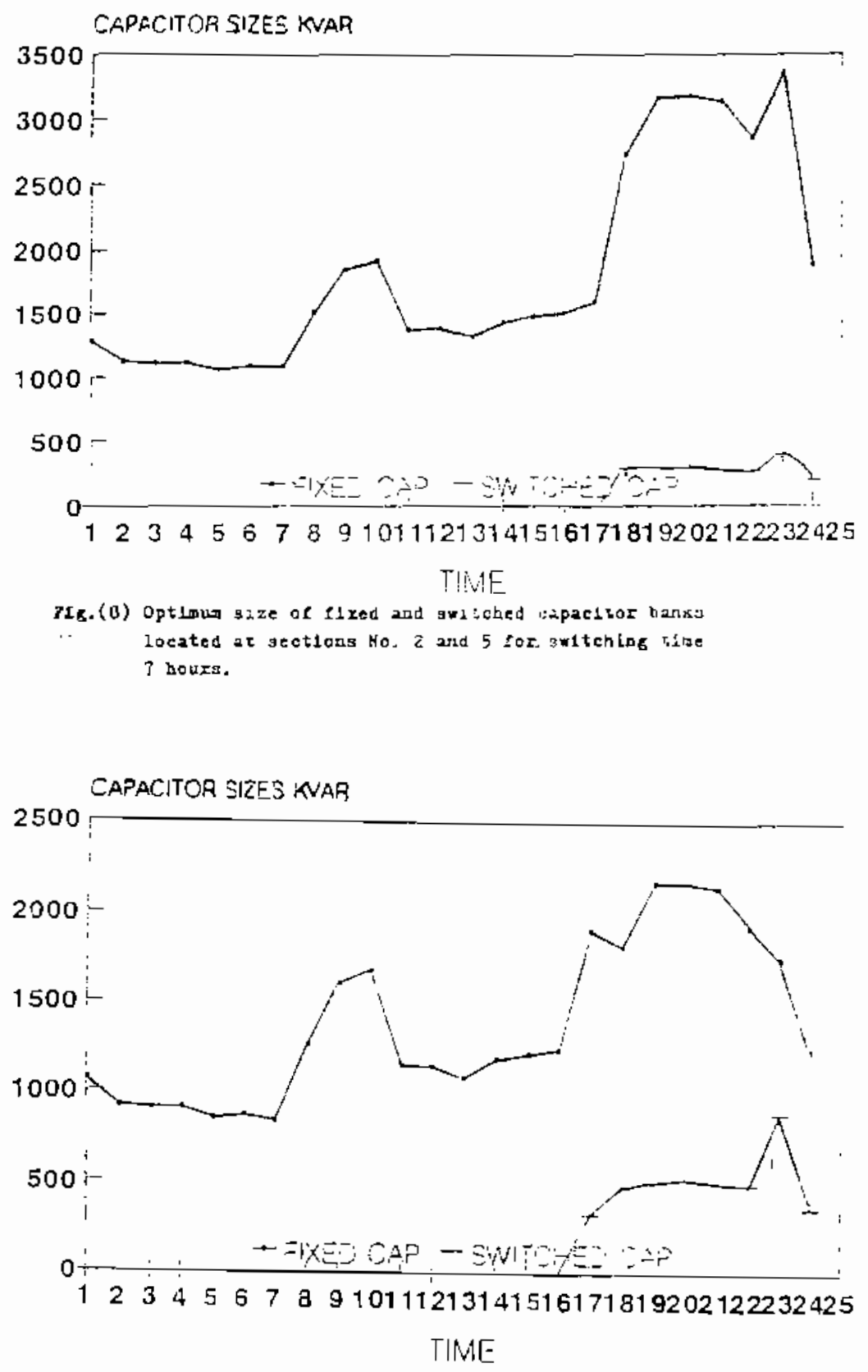

P15. (g) Optimun alze of flxed and awhtelied capactior banks

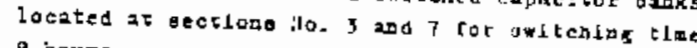
9 noura. 


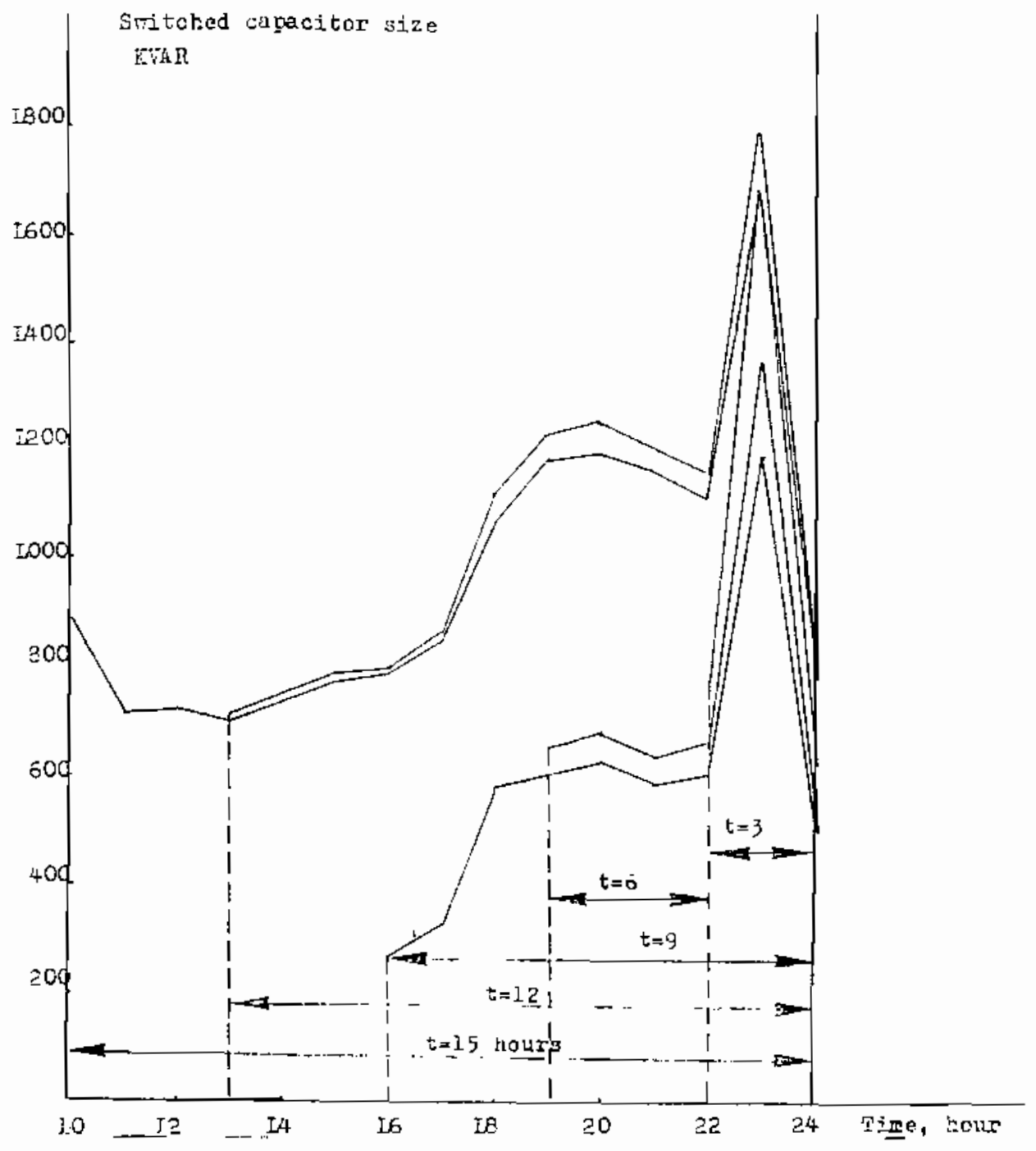

P1g.10 5wltohed capacitor size-time characteristic rith owitching time $3,0,9,12,15$, hours, Etxed eapacitor locates at gecton 3 and awitched napacitar ac gection 4 . 


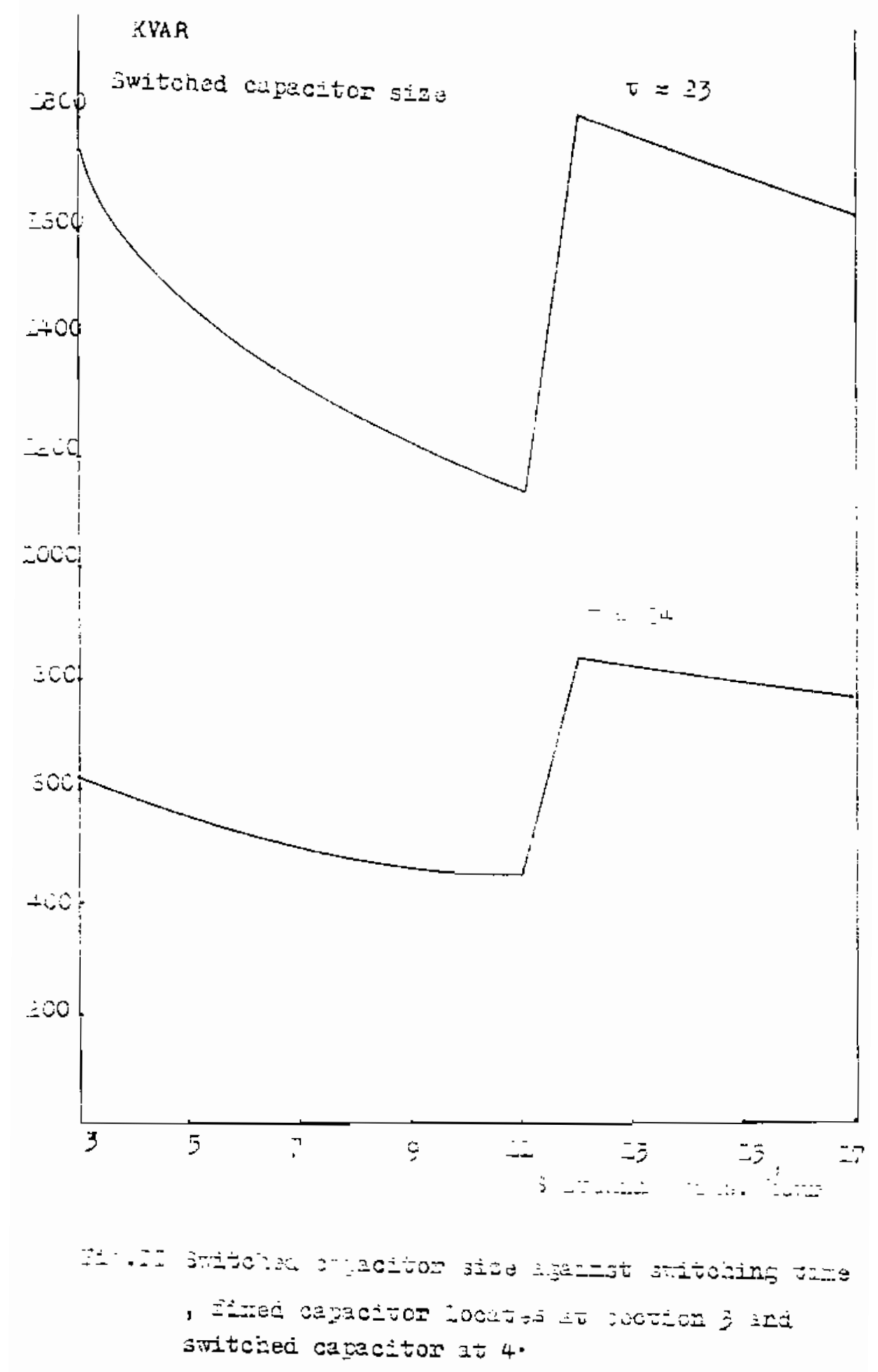

